Saudi Journal of Oral and Dental Research

Abbreviated Key Title: Saudi J Oral Dent Res ISSN 2518-1300 (Print) |ISSN 2518-1297 (Online) Scholars Middle East Publishers, Dubai, United Arab Emirates Journal homepage: https://saudijournals.com/sjodr

\title{
Endodontist Attitude towards Single Sitting versus Multiple Sitting Rcts in Non-Infected Posterior Teeth- A Qualitative Research
}

Dr. Digvijaysinh Parmar ${ }^{1 *}$, Dr. Kumudhati Tiwari ${ }^{2}$, Dr. Harshitha Garlapati ${ }^{3}$, Dr. Priya Shah ${ }^{4}$, Dr. Anum Khurshid ${ }^{5}$, Dr. Rashmi Kolichala $^{6}$

${ }^{1}$ BDS, MPH, PMNM Dental College and Hospital, Karnataka, India

${ }^{2}$ BDS, BRS Dental College and Hospital, Haryana, India

${ }^{3}$ BDS, Narayana Dental College and Hospital, Nellore, Andhra Pradesh, India

${ }^{4}$ BDS, Darshan Dental College and Hospital, Loyara, Udaipur, India

${ }^{5}$ BDS, Georgia, United States

${ }^{6}$ BDS, MPA, Sri Venkata Sai Institute of Dental Sciences, Telangana, India

DOI: $10.36348 /$ sjodr.2020.v05i04.004 $\quad$ |Received: 01.04.2020 | Accepted: 13.04.2020 | Published: 15.04 .2020

*Corresponding author: Dr. Digvijaysinh Parmar

\section{Abstract}

Aim of the study: This study was conducted to demonstrate which treatment option was preferable for the endodontists between single sitting versus multiple sitting Root Canal treatment for posterior teeth. Materials and methods: A questionnaire survey was conducted in 30 Endodontists to understand their knowledge and selection of cases where single or multiple sitting RCTs are preferred over a time period of a year. Results: Single visit therapy is mostly practiced by practically $65.0 \%$ of all endodontists interviewed in cases of vital pulp, but when the biological status of the pulp progresses to being necrotic, then very few still choose this treatment type. Anterior teeth were mostly done in a single sitting as compared to posterior teeth RCTs. Conclusion: The practitioner should not routinely apply one technique to all situations, but rather evaluate the circumstances peculiar to each particular case and then choose the technique that best fits those circumstances

Keywords: Root Canal Therapy, single sitting RCT, post-operative healing.

Copyright @ 2020: This is an open-access article distributed under the terms of the Creative Commons Attribution license which permits unrestricted use, distribution, and reproduction in any medium for non-commercial use (NonCommercial, or CC-BY-NC) provided the original author and source are credited.

\section{INTRODUCTION}

Endodontic treatment also known as endodontic therapy or root canal treatment (RCT) includes the elimination of diseased pulpal tissue to prevent and intercept pulpal/peri-radicular pathosis and fortification of the disinfected tooth from future entrenchment by microorganisms [1]. Traditionally, root canal treatment was done in multiple visits, with the use of additional disinfecting agents (intracanal dressing) besides the irrigants that is used during the cleaning and shaping procedure which largely aims to diminish microorganisms and their by-products from the root canal system before obturation. Advances in endodontics like NiTi instruments, apex locators, biocompatible sealing systems have led to surge in incidence of Single visit Endodontics in clinics nowadays [2]. Those who believe that efficacious root canal treatment can be completed in one visit have justification in literature. Studies concerning postoperative pain as well as healing rates shows the treatment outcome to be comparable whether completed in one or multiple visits. In addition to this, treatment in one visit offers many advantages. This decreases the number of operative procedures with additional anaesthesia, gingival trauma from rubber dam application as well as eradicating the risk of inter appointment leakage through temporary restoration. It is less laborious resulting in a reduced amount of cost to the patients [3]. Supporters of multiple visit procedures state that the antimicrobial property of interappointment calcium hydroxide placement is required to ensure successful peri-radicular healing [4], although expected levels of bacterial reduction via superior cleaning and shaping techniques is one appointment may negate this need [5]. Also, when flare-ups occur during multiple-visit procedures, they can be tackled prior to obturation. This is not an choice in a single-visit treatment regimen. When flare-ups occur, non-surgical re-treatment or surgical intervention is typically necessary [3]. Single visit root canal treatment is specified in cases of vital teeth with irreversible pulpitis, fractured anterior teeth where instantaneous rehabilitation is required because of aesthetic concern, teeth requiring intentional endodontic treatment such as 
teeth serving as overdenture abutments, physically challenged patients who cannot come several times, non-vital teeth which have sinus tract present. However necrotic teeth with periapical radiolucency has been thought of as contraindication for single visit RCT [6]. While post-operative pain is not the norms for success of endodontic treatment but it is still measured as parameter for success of endodontic treatment and of clinician's skills. Fear of post-operative pain is the main reason for avoiding single visit endodontic treatment as it is thought that there is more postoperative pain in single visit than multiple visit endodontic treatment. A huge number of studies have concluded that there is no substantial difference in the incidence of pain after treatment done in single and multiple visit [7]. In some studies, more occurrence of pain was detected when treatment was done in multiple-visit [8]. These facts create confusion for Endodontists, whether to perform single sitting or traditional multiple sitting RCTs which depends upon lot of factors like post-operative complications, pain etc. especially in cases of posterior teeth which are not acutely inflamed.

\section{AIM OF THE STUDY}

Clinicians have been doing single-visit and multiple-visit endodontic treatments for their patients. This study aims to compare the attitude of Endodontists based on success rate, incidence of postoperative pain and chairside time of single-visit and multiple-visit endodontic treatments.

\section{MATERIALS AND METHODS}

A questionnaire survey was conducted in 30 Endodontists to understand their knowledge and selection of cases where single or multiple sitting RCTs are preferred. It was e-mailed explaining the purpose of the study. The survey consisted of questions about treatment options, preferences and view about single and multiple visit canal treatment. The answers were entered into spread sheet software for analysis. Descriptive statistics were utilised.

\section{RESULTS}

In this study, participants consisted of $60 \%$ male and $40 \%$ female Endodontists. Most of them have more than three years of specialist practice $(60.5 \%)$. Almost $40 \%$ of all participants used NiTi files for canal preparation, primarily in crown-down technique whereas others use traditional hand files. The sodium hypochlorite is the irrigation substance of choice for $86 \%$ endodontists (Table-1). Regarding to the time to finish a single visit treatment, most part of the professionals described taking more than 90 minutes to complete the treatment of posterior teeth both for vital and necrotic pulp (41\% and 59\%, respectively). Single visit therapy is mostly practiced by practically $65.0 \%$ of all endodontists interviewed in cases of vital pulp, but when the biological status of the pulp progresses to being necrotic, then very few still choose this treatment type. Anterior teeth root canal were usually done in a single sitting with minimal complications whereas posterior teeth sometimes required multiple sittings.

Nevertheless, most of participants were keen to provide single visit treatment in cases of necrotic pulp without periapical lesion $(52.5 \%)$ rather than in cases with periapical lesion $(75 \%)$. When questioned about what were the most common reasons for not conducting a single visit therapy in teeth with pulp necrosis with or without periapical lesion, $55.5 \%$ of the participants replied about the "importance of the intracanal medication". Alternatively, when asked about the chief reason to perform a single visit treatment, $80.4 \%$ of the professionals responded that vital pulp is the most vital aspect. The most important reason to permit this treatment type was the absence of exudate for $92.0 \%$ of them (Table-2).

Table-1: Characteristics noted in present survey

\begin{tabular}{|l|l|}
\hline Gender of clinicians surveyed & $60 \%$ \\
\hline Male & $40 \%$ \\
\hline Female & $60.5 \%$ \\
\hline Years of experience as an Endodontist & $39.5 \%$ \\
\hline$>$ 3years & \multicolumn{2}{|l|}{} \\
\hline <3 years & $60 \%$ \\
\hline Choice of instruments for RCT & $40 \%$ \\
\hline Traditional hand filing & $86 \%$ \\
\hline NiTi files (Nickel Titanium files) & $14 \%$ \\
\hline Choice of irrigation chemical to be used in canals & $41 \%$ \\
\hline Sodium hypochlorite & $59 \%$ \\
\hline Others & \\
\hline Procedure time for single sitting RCT in posterior teeth (more than 90 mins) \\
\hline Teeth with Vital pulp & \multicolumn{2}{|l|}{} \\
\hline Teeth with Necrotic Pulp &
\end{tabular}


Digvijaysinh Parmar et al; Saudi J Oral Dent Res, April, 2020; 5(4): 223-226

Table-2: Points favouring Multiple sitting RCTs versus Single sitting RCTs respectively. (Endodontists favoured multiple reasons for and against each type of RCT)

\begin{tabular}{|l|l|}
\hline Multiple sitting RCT & Single sitting RCT \\
\hline Intracanal medication effect needs time (55.5\%) & Pulp which is vital (80.4\%) \\
\hline Post-operative pain (38\%) & Between the appointment Infection in canals (45\%) \\
\hline Biological healing uncertainties (42\%) & Absence of any peri-apical lesion/exudate (92\%) \\
\hline Flare-up of the lesion (18\%) & Single visit patient preference (12\%) \\
\hline Others (2\%) & Others (time constraint etc.) (3\%) \\
\hline
\end{tabular}

\section{DISCUSSION}

The chairside time for single-visit treatment was obviously shorter than multiple-visit treatment. It is also seen that single-visit non-surgical primary endodontic treatment could be performed by general dentists with a reasonable success rate. The chief consideration for general practitioners is case selection [9]. Even ensuring best possible disinfection by biomechanical preparation and irrigation of canals, bacteria usually persist within the root canal system. Essentially, success of RCT is based primarily on eliminating microorganisms and creation of an environment which is most favourable for healing. This may be achieved either in one visit or in multiple visits, where dressings are placed in between the appointments. Typically, endodontists favour to carry out RCT of vital teeth in a single visit [10]. Ferranti reported comparatively low incidence of server pain subsequent single visit procedure [11]. O'Keefe found no noteworthy difference in postoperative pain experience by his patient ensuing single visit or multiple visit root canal treatment [12]. Soltanoff used a random collection of cases treated during 1 year period to compare single and multiple visit treatment by degree of postoperative pain experienced found subsequently after single visit treatment more than $50 \%$ of his patient experienced pain [13]. Roane et al., stated a 2:1 higher frequency of pain following treatment accomplished in multiple visit as compared to that described for those treated with single visit [14]. Mulhern et al determined that there was no noteworthy difference in the incidence of postoperative pain between one-visit and multiplevisit endodontic treatment of asymptomatic pulpal necrosis [15]. In this present study, most interviewed endodontists reported the use of hand files and the Crown-Down technique. It has been shown that this technique can diminish the chance of accretion of smear-layer in the apical area, refining the prognosis of immediate obturation Also, some studies showed that shaping the canal by using Crown-Down philosophy delivers a cleaner apical third of the root canals [16].

\section{CONCLUSION}

Both single and multi-visit treatments should be viewed as part of a total endodontic treatment spectrum, with the choice of one over the other being determined by the circumstances surrounding each individual case. The practitioner should not routinely apply one technique to all situations, but rather evaluate the circumstances peculiar to each particular case and then choose the technique that best fits those circumstances.

\section{REFERENCES}

1. Bansal, R., \& Jain, A. (2020). An insight into patient's perceptions regarding root canal treatment: A questionnaire-based survey. Journal of Family Medicine and Primary Care, 9(2), 10201027.

2. Al-Rahabi, M., \& Abdulkhayum, A. M. (2012). Single visit root canal treatment. Saudi Endodontic Journal, 2(2), 80-84.

3. Singla, R., Marwah, N., \& Dutta, S. (2008). Single visit versus Multiple visit root canal therapy. International journal of clinical pediatric dentistry, 1(1), 17-24.

4. Byström, A., \& Sunvqvist, G. (1985). The antibacterial action of sodium hypochlorite and EDTA in 60 cases of endodontic therapy. International endodontic journal, 18(1), 35-40.

5. Card, S. J., Sigurdsson, A., Ørstavik, D., \& Trope, M. (2002). The effectiveness of increased apical enlargement in reducing intracanal bacteria. Journal of Endodontics, 28(11), 779-783.

6. Inamoto, K., Kojima, K., Nagamatsu, K., Hamaguchi, A., Nakata, K., \& Nakamura, H. (2002). A survey of the incidence of single-visit endodontics. Journal of Endodontics, 28(5), 371374.

7. Eleazer, P. D., \& Eleazer, K. R. (1998). Flare-up rate in pulpally necrotic molars in one-visit versus two-visit endodontic treatment. Journal of endodontics, 24(9), 614-616.

8. Albashaireh, Z. S. M., \& Alnegrish, A. S. (1998). Postobturation pain after single-and multiple-visit endodontic therapy. A prospective study. Journal of dentistry, 26(3), 227-232.

9. Wong, A. W. Y., Tsang, C. S. C., Zhang, S., Li, K. Y., Zhang, C., \& Chu, C. H. (2015). Treatment outcomes of single-visit versus multiple-visit nonsurgical endodontic therapy: a randomised clinical trial. BMC oral health, 15(1), 162.

10. Alomaym, M. A. A., Aldohan, M. F. M., Alharbi, M. J., \& Alharbi, N. A. (2019). Single versus multiple sitting endodontic treatment: Incidence of postoperative pain-A randomized controlled trial. Journal of International Society of Preventive \& Community Dentistry, 9(2), 172-177. 
11. Ferranti, P. (1959). Treatment of the root canal of an infected tooth in one appointment: a report of 340 cases. Dent Dig, 65(11), 490-94.

12. O'Keefe, E. M. (1976). Pain in endodontic therapy: preliminary study. Journal of endodontics, 2(10), 315-319.

13. Soltanoff, W. (1978). A comparative study of the single-visit and the multiple-visit endodontic procedure. Journal of Endodontics, 4(9), 278-281.

14. Roane, J. B., Dryden, J. A., \& Grimes, E. W. (1983). Incidence of postoperative pain after single-and multiple-visit endodontic procedures. Oral Surgery, Oral Medicine, Oral Pathology, 55(1), 68-72.

15. Mulhern, J. M., Patterson, S. S., Newton, C. W., \& Ringel, A. M. (1982). Incidence of postoperative pain after one-appointment endodontic treatment of asymptomatic pulpal necrosis in single-rooted teeth. Journal of endodontics, 8(8), 370-375.

16. de Souza Netto, M., Saavedra, F., Júnior, J. S., Machado, R., Silva, E. J. N. L., \& Vansan, L. P. (2014). Endodontists perceptions of single and multiple visit root canal treatment: a survey in Florianópolis-Brazil. RSBO Revista Sul-Brasileira de Odontologia, 11(1), 14-19. 